The Journal of Laryngology \& Otology

http://journals.cambridge.org/JLO

Additional services for The Journal of Laryngology \& Otology:

Email alerts: $\underline{\text { Click here }}$

Subscriptions: $\underline{\text { Click here }}$

Commercial reprints: Click here

Terms of use : $\underline{\text { Click here }}$

\title{
Clinical value of tone burst vestibular evoked myogenic potentials at threshold in acute and stable Ménière's disease
}

V Osei-Lah, B Ceranic and L M Luxon

The Journal of Laryngology \& Otology / Volume 122 / Issue 05 / May 2008, pp 452 - 457

DOI: 10.1017/S0022215107009152, Published online: 03 July 2007

Link to this article: http://journals.cambridge.org/abstract_S0022215107009152

How to cite this article:

V Osei-Lah, B Ceranic and L M Luxon (2008). Clinical value of tone burst vestibular evoked myogenic potentials at threshold in acute and stable Ménière's disease. The Journal of Laryngology \& Otology, 122, pp 452-457 doi:10.1017/ S0022215107009152

Request Permissions : $\underline{\text { Click here }}$ 


\title{
Clinical value of tone burst vestibular evoked myogenic potentials at threshold in acute and stable Ménière's disease
}

\author{
V Osei-Lah, B Ceranic*, L M Luxon
}

\begin{abstract}
Introduction: The objectives of this preliminary, prospective, cohort study were to ascertain the characteristics of vestibular evoked myogenic potentials at threshold levels in two groups of Ménière's disease patients - acute and stable - and to identify whether vestibular evoked myogenic potentials can provide any specific, objective information to distinguish acute from stable Ménière's disease.

Subjects and methods: The study was based at a tertiary neuro-otology centre. Twenty adult patients who fulfilled the American Academy of Otolaryngology-Head and Neck Surgery ${ }^{1}$ criteria for Ménière's disease were divided into two groups: 11 patients with acute Ménière's disease and nine patients with stable Ménière's disease. Eighteen healthy adult volunteers served as controls. All subjects underwent vestibular evoked myogenic potential testing with ipsilateral, short tone burst stimuli at $500 \mathrm{~Hz}$, as well as pure tone audiometry. The patients also underwent caloric testing.

Results: Vestibular evoked myogenic potentials were present in all controls, and were present in 65 per cent of patients but absent in 35 per cent. The mean absolute threshold ( ${ }_{T}$ vestibular evoked myogenic potential $) \pm$ standard deviation in normal controls was $116 \pm 7.7 \mathrm{dBSPL}$; this did not differ statistically from that in patients, nor did it differ between acute and stable Ménière's disease. The p13/n23 latencies at the threshold levels in the normal, acute and stable groups (mean \pm standard deviation) were respectively: $15 \pm 2.2 \mathrm{~ms} / 23.0 \pm 2.5 \mathrm{~ms} ; 15.7 \pm 0.9 \mathrm{~ms} / 23.7 \pm 0.9 \mathrm{~ms} ;$ and $15.3 \pm 2.0 \mathrm{~ms} / 24.2 \pm$ $1.9 \mathrm{~ms}$. The mean interaural amplitude difference ratio (IAD) \pm standard deviation was significantly higher in the stable group compared with the acute group $(0.54 \pm 0.33 v s-0.15 \pm 0.22 ; p=0.007)$ and with the controls $(0.54 \pm 0.33$ vs $0.1 \pm 0.22 ; p=0.05)$.

Conclusions: The parameter that best differentiated acute from stable Ménière's disease at threshold was the interaural amplitude difference ratio. Therefore, this parameter may be used to monitor the clinical course of Ménière's disease.
\end{abstract}

Key words: Ménière's Disease; Evoked Potentials; Vestibular Function Tests

\section{Introduction}

The recording of vestibular evoked myogenic potentials is emerging as a useful tool in clinical vestibular practice. Clinical and experimental studies have suggested that vestibular evoked myogenic potentials are generated by saccular afferents in response to loud acoustic stimuli, and may be recorded by surface electrodes on a tonically contracted sternocleidomastoid muscle. ${ }^{2,3}$ The putative pathway for ipsilateral vestibular evoked myogenic potential is the saccule, inferior vestibular nerve, lateral vestibular nucleus, lateral vestibulospinal tract and the sternocleidomastoid muscle (Figure 1).
Ménière's disease is an inner-ear disorder with an entirely unpredictable clinical course. The pathophysiology is unknown, although endolymphatic hydrops is believed to be the main histopathological correlate. The disease in its typical form is characterised by acute phases (exacerbation), with attacks of aural fullness, vertigo, tinnitus and hearing loss, separated by variable periods of remission (stable phase). The underlying mechanism for such a clinical course is unclear. Furthermore, at present, several tests are used to characterise Ménière's disease, including the caloric test, electronystagmography, electrocochleography and osmotic tests. However, results are highly variable, 


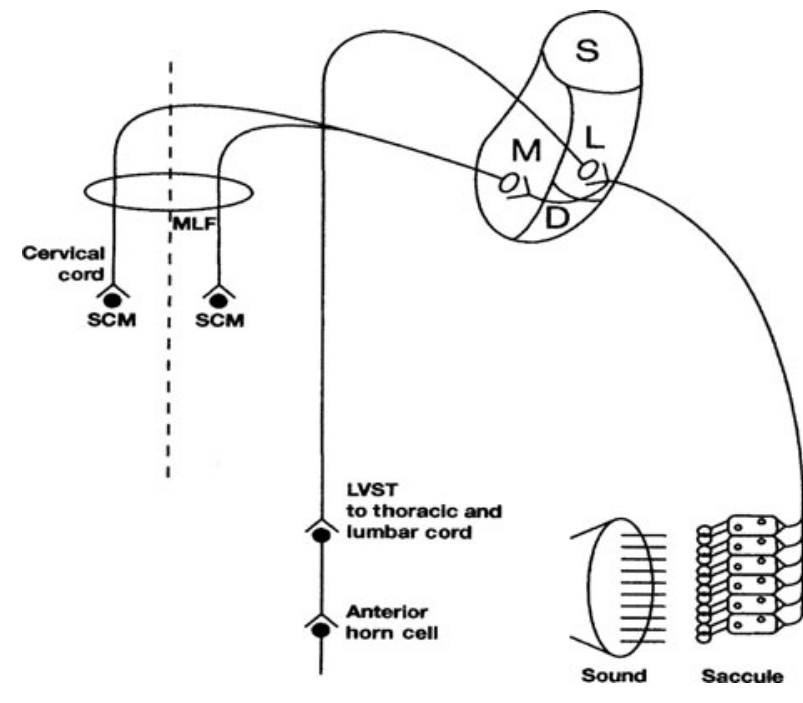

FIG. 1

Pathway for ipsilateral vestibular evoked myogenic potential. $\mathrm{S}=$ superior vestibular nucleus; $\mathrm{M}=$ medial vestibular nucleus; $\mathrm{L}=$ lateral vestibular nucleus; $\mathrm{D}=$ descending vestibular nucleus; LVST = lateral vestibulospinal tract; $\mathrm{MLF}=$ medial longitudinal fasciculus; SCM = sternocleidomastoid muscle.

such that no one test is diagnostic. Moreover, all these tests may cause some degree of discomfort.

Vestibular evoked myogenic potentials are thought to provide specific information about the saccule, which, according to histological studies, is the most common site of morphological alteration in the vestibular labyrinth. ${ }^{4,5}$ Thus, the recording of vestibular evoked myogenic potentials could be a suitable test for Ménière's disease, as it is easy to perform, non-invasive and well tolerated. It is therefore anticipated that vestibular evoked myogenic potentials could be used in cases of Ménière's disease to: aid understanding of the pathophysiology; aid diagnosis ( particularly regarding early detection of contralateral ear involvement); and monitor the clinical course of the disease.

There have been a number of reports on vestibular evoked myogenic potentials in Ménière's disease, with variable results.

De Waele et al. ${ }^{6}$ studied 59 patients with Ménière's disease and reported absent vestibular evoked myogenic potentials (in response to clicks) in 54 per cent of patients; this result correlated with the degree of low frequency hearing loss and poor postural performance, but not with canal paresis.

Seo et $a l .^{7}$ reported a case of saccular hydrops in a patient presenting with non-rotatory disequilibrium, in which a depressed vestibular evoked myogenic potential amplitude recovered to normal after furosemide administration. The same group ${ }^{8}$ subsequently demonstrated an increase in p13-n23 amplitude in seven of 18 cases and the reappearance of vestibular evoked myogenic potentials in three out of seven cases after furosemide loading. These results suggest that reversal of reflex attenuation is due to reduction of saccular hydrops following diuresis However, in those in whom vestibular evoked myogenic potentials remained absent after furosemide loading, severe hydrops might have caused irreversible saccular degeneration.

Detection of either absent or reduced vestibular evoked myogenic potential amplitudes has been widely reported. ${ }^{9-12}$ Kuo et al. ${ }^{13}$ reported abnormal vestibular evoked myogenic potentials (absent or depressed) in eight out of 12 Ménière's disease patients within 24 hours of an acute attack; however, in four of those patients, vestibular evoked myogenic potentials returned to normal after 48 hours. These authors postulated that abnormal vestibular evoked myogenic potentials were due to saccular hydrops affecting oscillation of the endolymph, whereas the reappearance of vestibular evoked myogenic potentials could be attributed to drainage of the saccular hydrops.

Although most studies have focussed on amplitude changes, recent reports indicate that threshold is probably a more reliable measure of vestibular evoked myogenic potential changes in Ménière's disease. ${ }^{14,15}$ Lin et al. ${ }^{15}$ reported elevated mean vestibular evoked myogenic potential thresholds in affected ears and also, to a lesser extent, in contralateral asymptomatic ears, compared with normal controls. They concluded that vestibular evoked myogenic potentials could be used to predict contralateral ear involvement and eventual bilateral Ménière's disease.

The distinct characteristics of vestibular evoked myogenic potentials in acute and stable Ménière's disease are unknown. Therefore, this study examined vestibular evoked myogenic potentials in normal subjects and in patients with Ménière's disease, and also compared results for patients in the acute and stable phases of the disease.

\section{Materials and methods}

\section{Subjects}

Twenty patients who fulfilled the American Academy of Otolaryngology-Head and Neck Surgery $^{1}$ criteria for Ménière's disease, and who attended a tertiary neuro-otology clinic at the National Hospital for Neurology and Neurosurgery, London, were recruited for the study. All patients were interviewed to obtain a full clinical history and underwent a full clinical neuro-otological examination. The acute (exacerbation) group (11 patients) consisted of those who had had an attack in the preceding three months and were still symptomatic. The stable (remission) group (nine patients) had been free of attacks and symptoms for more than three months. Eighteen healthy volunteers (36 ears) aged between 18 and 60 years, with no history of neurological or otological disease, acted as controls.

The study was approved by the joint ethics committee of the National Hospital for Neurology and Neurosurgery and the Institute of Neurology.

\section{Methods}

Audiovestibular tests. Pure tone audiometry was performed in all subjects. ${ }^{16}$ The patients also underwent immitance audiometry, ${ }^{16}$ transient evoked 
oto-acoustic emissions, ${ }^{17}$ direct current electronystagmography, and caloric testing by the FitzgeraldHallpike technique, according to the standard protocol of the National Hospital for Neurology and Neurosurgery, neuro-otology department. ${ }^{18}$

Recording of vestibular evoked myogenic potentials. The sternocleidomastoid muscle was used as the target muscle. Subjects were tested while laying on a couch with the head rest adjusted $30^{\circ}$ to the horizontal plane. Surface electromyography (EMG) was recorded by attaching $\mathrm{Ag} / \mathrm{AgCl}$ electrodes on the mid-point of the sternocleidomastoid muscle (active), the mid-clavicle (negative) and the upper sternum (ground). From the recumbent position, subjects were instructed to lift their head up, in order to activate both sternocleidomastoid muscles symmetrically; a $500 \mathrm{~Hz}$ short tone burst (1 ms rise and fall, $2 \mathrm{~ms}$ plateau) was then delivered via TDH 49 calibrated headphones (Telephonics Corporation, New York, New York, USA), mono-aurally at a rate of $4.7 \mathrm{~Hz}$, using the Medelec Synergy EMG/EP system (Oxford Instruments Limited, Surrey, UK). Tone bursts instead of clicks were used because the former involved less scatter of energy at suprathreshold level. A frequency of $500 \mathrm{~Hz}$ was used because this is the frequency reported to best differentiate normal from abnormal responses at threshold. ${ }^{19}$ Electromyographic signals were amplified, band pass filtered between 20 and $2000 \mathrm{~Hz}$, and sampled for $100 \mathrm{~ms}$. Two hundred stimuli were averaged for each test run. The stimulus was delivered at 130 dBSPL to elicit the initial positive (p13) and negative (n23) waves ipsilateral to the stimulus (Figure 2). The stimulus was then reduced in $5 \mathrm{~dB}$ steps and the minimum intensity required to elicit a p13-n23 response was taken to be the threshold of stimulation, designated $\mathrm{T}^{\text {vestibular evoked myogenic }}$ potential. For each p13-n23 waveform, the peak-to-peak amplitude of the unrectified EMG was measured, as was the amplitude of the rectified EMG which reflected the degree of muscle activation. The latencies of $\mathrm{p} 13$ and $\mathrm{n} 23$ were measured and the interaural amplitude difference and ratio, as well as the interaural threshold difference and ratio, were computed.

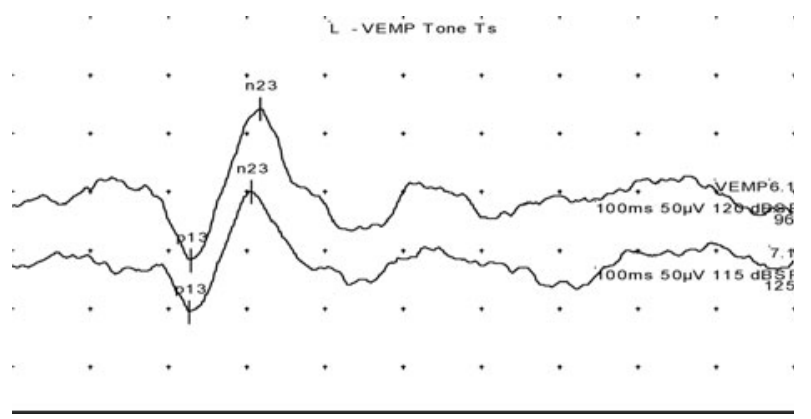

FIG. 2

Vestibular evoked myogenic potential (VEMP) p13/n23 wave complex.
The Statistical Package for the Social Sciences version 11 software (SPSS Inc, Chicago, Illinois, USA) was used for data analyses. The Student $t$-test was used to compare the results of the two patient groups, side-to-side differences, and differences between affected ears and control ears.

Comparisons of the results for the three subject groups were performed using one-way analysis of variance, with Bonferroni corrections for multiple comparisons. A significance level of 0.05 was used.

\section{Results and analysis}

The study included 12 female and six male controls with a mean age of 34.1 years (standard deviation (SD), 5.9 years; range, 26-49 years).

The characteristics of the patients are summarised in Table I. The mean age of the Ménière's disease patients was 48.5 years (SD, 11.3 years; range, 2061 years) and their median duration of illness was 4.5 years (range, 1-22 years). There were 10 women and 10 men. Eleven (55 per cent) patients had acute Ménière's disease and nine (45 per cent) had stable disease. In 11 (55 per cent) and nine (45 per cent) patients, the affected side was the left and right, respectively. According to the American Academy of Otolaryngology-Head and Neck Surgery criteria, 16 (80 per cent) were classified as having definite Ménière's disease, whereas two (10 per cent) each had possible and probable disease.

Four patients had normal caloric test responses, and one patient did not undergo the test because of an in situ grommet. The remaining patients had significant canal paresis in the affected ear, ranging between 8 and 100 per cent (normal canal paresis, for this department, was less than 8 per cent) (Table I).

\section{Vestibular evoked myogenic potential results}

The mean \pm SD threshold (Tvestibular evoked myogenic potential) for the controls (36 ears) was $116 \pm$ 7.7 dBSPL $( \pm 104.5$ dBnHL). Vestibular evoked myogenic potentials were present in 13 (65 per cent) of the 20 affected ears. Of the seven (35 per cent) affected ears without a measurable vestibular evoked myogenic potential, two had acute disease and five had stable disease. Thus, vestibular evoked myogenic potentials were recorded in 81 per cent of the acute group but in only 44 per cent of the stable group. There was no correlation between the duration of Ménière's disease and the presence or absence of vestibular evoked myogenic potentials. The mean $\pm \mathrm{SD}_{\mathrm{T}}$ vestibular evoked myogenic potential for the affected ears in the acute and stable groups were respectively $118 \pm 7.9 \mathrm{dBSPL}$ and $120 \pm 4.0$ dBSPL. The same parameter in nonaffected patient ears was $117 \pm 5.3 \mathrm{dBSPL}$. There was no statistical difference in ${ }_{T}$ vestibular evoked myogenic potential between acute and stable patients, control ears and affected ears, and control ears and non-affected ears (Table II).

Twelve patients underwent vestibular evoked myogenic potential testing for both sides (affected and non-affected). Of these, vestibular evoked myogenic potentials were absent bilaterally in three, absent on 
TABLE I

CHARACTERISTICS OF MÉNIÈRE'S DISEASE PATIENTS

\begin{tabular}{|c|c|c|c|c|c|c|c|c|}
\hline Subject & Sex & Age (yr) & Acute/stable MD & MD side & MD class & MD duration (yr) & Canal paresis $(\%)$ & VEMP present? \\
\hline 1 & $\mathrm{~F}$ & 36 & Acute & $\mathrm{L}$ & Definite & 10 & 100 & $\mathrm{Y}$ \\
\hline 2 & $\mathrm{~F}$ & 40 & Acute & $\mathrm{L}$ & Definite & 3 & 10 & $\mathrm{~N}$ \\
\hline 3 & $\mathrm{M}$ & 50 & Acute & $\mathrm{R}$ & Possible & 4 & 78 & $\mathrm{Y}$ \\
\hline 4 & $\mathrm{M}$ & 61 & Acute & $\mathrm{L}$ & Definite & 10 & NA & $\mathrm{Y}$ \\
\hline 5 & $\mathrm{~F}$ & 60 & Acute & $\mathrm{R}$ & Definite & 3 & 8 & $\mathrm{Y}$ \\
\hline 6 & $\mathrm{~F}$ & 20 & Acute & $\mathrm{L}$ & Probable & 5 & 39 & $\mathrm{Y}$ \\
\hline 7 & M & 49 & Acute & $\mathrm{L}$ & Definite & 3 & 20 & $\mathrm{Y}$ \\
\hline 8 & $\mathrm{M}$ & 61 & Acute & $\mathrm{R}$ & Definite & 10 & 8 & $\mathrm{~N}$ \\
\hline 9 & $\mathrm{M}$ & 48 & Acute & $\mathrm{R}$ & Definite & 2 & 9 & $\mathrm{Y}$ \\
\hline 10 & $\mathrm{M}$ & 58 & Acute & $\mathrm{L}$ & Definite & 1 & 13 & $\mathrm{Y}$ \\
\hline 11 & $\mathrm{~F}$ & 53 & Acute & $\mathrm{R}$ & Definite & 6 & 51 & $\mathrm{Y}$ \\
\hline 12 & $\mathrm{~F}$ & 58 & Stable & $\mathrm{R}$ & Possible & 6 & 20 & $\mathrm{Y}$ \\
\hline 13 & $\mathrm{M}$ & 51 & Stable & $\mathrm{L}$ & Definite & 10 & 20 & $\mathrm{~N}$ \\
\hline 14 & M & 52 & Stable & $\mathrm{L}$ & Definite & 4 & NA & $\mathrm{N}$ \\
\hline 15 & $\mathrm{~F}$ & 41 & Stable & $\mathrm{R}$ & Probable & 1 & Grommet & $\mathrm{Y}$ \\
\hline 16 & $\mathrm{~F}$ & 39 & Stable & $\mathrm{L}$ & Definite & 8 & 15 & $\mathrm{~N}$ \\
\hline 17 & $\mathrm{M}$ & 28 & Stable & $\mathrm{L}$ & Definite & 3 & 5 & $\mathrm{~N}$ \\
\hline 18 & $\mathrm{~F}$ & 50 & Stable & $\mathrm{L}$ & Definite & 2 & 17 & $\mathrm{Y}$ \\
\hline 19 & $\mathrm{~F}$ & 54 & Stable & $\mathrm{R}$ & Definite & 22 & 15 & $\mathrm{Y}$ \\
\hline 20 & $\mathrm{M}$ & 60 & Stable & $\mathrm{R}$ & Definite & 8 & NA & $\mathrm{N}$ \\
\hline
\end{tabular}

$\mathrm{Yr}=$ years; $\mathrm{MD}=$ Ménière's disease; $\mathrm{VEMP}=$ vestibular evoked myogenic potential; $\mathrm{F}=\mathrm{female} ; \mathrm{M}=\mathrm{male} ; \mathrm{L}=\mathrm{left} ; \mathrm{R}=\mathrm{right}$; $\mathrm{Y}=$ yes; $\mathrm{N}=$ no; $\mathrm{NA}=$ no asymmetry

the diseased side only in two and absent on the nondiseased side in a further two patients. Thus, in five patients, vestibular evoked myogenic potentials were absent in the non-affected ear.

The mean \pm SD p13 and n23 latencies at threshold in the controls were respectively $15 \pm 2.2 \mathrm{~ms}$ and $23 \pm$ $2.5 \mathrm{~ms}$. Statistically, these results did not differ from the respective results for the affected ears in the acute group $(15.7 \pm 0.9 \mathrm{~ms}$ and $23.7 \pm 0.9 \mathrm{~ms})$, the stable group $(15.3 \pm 2.0 \mathrm{~ms}$ and $24.2 \pm 1.9 \mathrm{~ms})$ or the non-affected Ménière's disease ears $(15.1 \pm 0.8 \mathrm{~ms}$ and $23.6 \pm 1.1 \mathrm{~ms})$. Although absolute latencies in the patients were within normal limits, p13 latency was shorter with longer duration of Ménière's disease $(\mathrm{R}=-0.73 ; p=0.004)$ (Figure 3).

The mean \pm SD corrected amplitudes (the ratio of tonic EMG and amplitude) did not differ between groups, being $1.7 \pm 0.5,1.9 \pm 0.5$ and $2.5 \pm 1.1$ for normal controls, acute ears and stable affected ears, respectively. The mean $\pm \mathrm{SD}$ interaural amplitude difference ratios (i.e. right to left amplitude difference divided by the sum of amplitudes) for controls and for acute and stable Ménière's disease affected ears were respectively $0.1 \pm 0.22,-0.15 \pm 0.22$ and $0.54 \pm 0.33$. The mean $\pm \overline{S D}$ interaural amplitude difference ratio was significantly higher in the stable group compared with the acute group $(0.54 \pm 0.33$ vs $-0.15 \pm 0.22 ; p=0.007)$ and with the controls $(0.54 \pm 0.33$ vs $0.1 \pm 0.22 ; p=0.05)$. Interaural threshold difference and interaural threshold difference ratios were determined for all groups, but differences did not reach statistical significance.

\section{Discussion}

This study compared vestibular evoked myogenic potential characteristics at threshold levels in patients with acute and stable Ménière's disease, using $500 \mathrm{~Hz}$ short tone burst stimuli. It has been widely reported that vestibular evoked myogenic potentials are frequency-sensitive in healthy individuals, as reflected in the 'frequency tuning curves'. Although Todd et al. ${ }^{20}$ reported maximum vestibular evoked myogenic potential amplitude responses of between 300 and $350 \mathrm{~Hz}$, the optimum frequency of the tone burst in healthy adults has been reported to be $500 \mathrm{~Hz} .^{19,21}$ In the study by Rauch et al., ${ }^{19}$ poorer tuning was apparent in Ménière's disease patients at $500 \mathrm{~Hz}$, and this was the frequency that best differentiated normal from diseased subjects. However, this 'best' frequency can lie between 500 and $1000 \mathrm{~Hz}^{22}$ or between 500 and $700 \mathrm{~Hz}^{23}$ The

TABLE II

VEMP CHARACTERISTICS OF CONTROLS AND OF AFFECTED AND NON-AFFECTED EARS

\begin{tabular}{|c|c|c|c|c|}
\hline \multirow[t]{2}{*}{ VEMP parameter } & \multirow[t]{2}{*}{ Controls } & \multicolumn{2}{|c|}{ Affected ears } & \multirow[t]{2}{*}{ Non-affected ears } \\
\hline & & Acute & Stable & \\
\hline${ }_{\mathrm{T}} \mathrm{VEMP}(\mathrm{dBSPL})$ & $116 \pm 7.7$ & $118 \pm 7.9$ & $120 \pm 4.0$ & $117 \pm 5.3$ \\
\hline $\mathrm{p} 13(\mathrm{~ms})$ & $15 \pm 2.2$ & $15.7 \pm 0.9$ & $15.3 \pm 2.0$ & $15.1 \pm 0.8$ \\
\hline n23 (ms) & $23.0 \pm 2.5$ & $23.7 \pm 0.9$ & $24.2 \pm 1.9$ & $23.6 \pm 1.1$ \\
\hline Amplitude $(\mu \mathrm{V})$ & $43.2 \pm 19.4$ & $39.2 \pm 19.9$ & $26.8 \pm 8.8$ & $60.8 \pm 58.5$ \\
\hline Corrected amplitude & $1.7 \pm 0.5$ & $1.9 \pm 0.5$ & $2.5 \pm 1.1$ & $2.0 \pm 1.2$ \\
\hline
\end{tabular}

Data are presented as mean \pm standard deviation. $\mathrm{VEMP}=$ vestibular evoked myogenic potential; ${ }_{\mathrm{T}} \mathrm{VEMP}=$ mean absolute VEMP threshold 


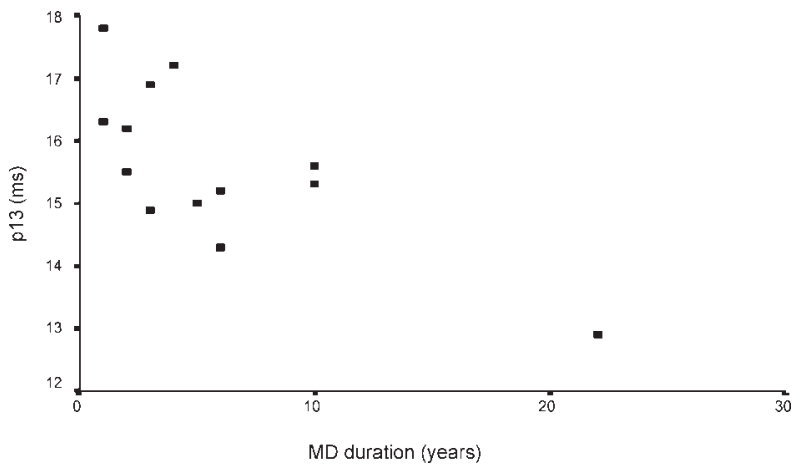

FIG. 3

Correlation between p13 latency and Ménière's disease duration.

alteration in tuning and threshold shift in Ménière's disease has been attributed to the presumed hydropic distension of the saccule. ${ }^{23}$

In this study, $\mathrm{T}$ vestibular evoked myogenic potential was $116 \pm 7.7 \mathrm{dBSPL}$. The threshold vestibular evoked myogenic potential response in healthy adults ranges between $110^{19}$ and 114.4 dBSPL. $^{22}$ The apparent differences may be due to differences in methodology.

Studies reporting threshold changes in Ménière's disease are few. In contrast to the present study, in which there was no statistically significant ${ }_{T}$ vestibular evoked myogenic potential difference between the ears of healthy volunteers and the affected and nonaffected ears of Ménière's disease patients, Rauch et $a l^{19}$ reported significantly elevated thresholds both in the affected and unaffected ears of Ménière's disease patients, compared with normal subjects. Lin et al., ${ }^{15}$ from the same centre, reported an elevated mean vestibular evoked myogenic potential threshold in affected ears and also, to a lesser extent, in the contralateral asymptomatic ears, compared with normal controls. These authors concluded that the vestibular evoked myogenic potential threshold can be used to predict contralateral ear involvement and eventual bilateral Ménière's disease; they also emphasised the importance of multifrequency testing to study the frequency tuning characteristics in Ménière's disease.

In the present study, the vestibular evoked myogenic potential parameter that best differentiated the three groups was the interaural amplitude difference ratio. This ratio was $0.10 \pm 0.22$ for controls, $-0.15 \pm 0.22$ for acute Ménière's disease affected ears and $0.54 \pm 0.33$ for stable Ménière's disease affected ears. In the literature, there is no information on values using tone burst, but for clickevoked vestibular evoked myogenic potential, a normal interaural amplitude difference ratio range of $0.14 \pm 0.11$ (mean \pm 1 SD) has been reported. ${ }^{9}$ These same authors reported a positive correlation between interaural amplitude difference ratios and the stage of disease, i.e. the higher the stage, the higher the ratio. This was not the case in our study, probably due to the small sample size. We found that the interaural amplitude difference ratio was significantly higher in stable disease when compared with acute disease $(p=0.007)$ and with controls $(p=0.05)$. Although the number of patients in our study was small, the interaural amplitude difference ratio appears to be a promising parameter for monitoring Ménière's disease progression; further research is needed to refine its clinical utility.

Rauch et al. ${ }^{14}$ reported that, in unilateral Ménière's disease, the interaural threshold difference correctly assigned side-of-disease in 85 per cent of cases. In this study, the interaural threshold difference did not vary between groups, probably due to differences in methodology and sample size.

- Vestibular evoked myogenic potentials are generated by saccular afferents in response to loud acoustic stimuli

- Ipsilateral vestibular evoked myogenic potentials specifically assess saccular function

- The saccule is the commonest vestibular site affected by Ménière's disease

- In this study, the interaural amplitude difference ratio appeared to be a valuable vestibular evoked myogenic potential parameter that differentiated between acute and stable Ménière's disease

- The interaural amplitude difference ratio may be useful in monitoring the clinical course of Ménière's disease

Latencies were normal in all groups. However, the p13 latency correlated negatively with the duration of Ménière's disease $(\mathrm{R}=-0.73 ; p=0.004)$. The $\mathrm{p} 13$ latency was shorter with a longer duration of Ménière's disease. The reason for this finding is not clear. Latency changes are believed to reflect changes within the central conducting pathways of the vestibular evoked myogenic potential reflex. Latency has been found to be stable in a variety of peripheral vestibular disorders, including Ménière's disease. ${ }^{11,24,25}$ Murofushi et al. ${ }^{24}$ also reported prolonged p13 latency both in patients with multiple sclerosis and in those with a large vestibular schwannoma compressing the brainstem. They concluded that lesions within the brainstem pathway of the vestibulospinal tract are a prerequisite for the prolongation of $\mathrm{p} 13$. Similar findings were reported by Alpini et al. ${ }^{26}$ who attributed the prolonged latencies in multiple sclerosis to demyelination, either of the primary afferent axons at the root entry zone or of secondary vestibulospinal tract axons. However, a few studies have reported prolonged p13 and n23 latencies in Ménière's disease, attributed to a high endolymphatic pressure in the saccule, impairing sound transmission. ${ }^{9,27}$ One possible explanation for the latency findings in this study could be retrograde degeneration in Scarpa's ganglion and the vestibular nerve, reducing the conduction velocity of the vestibular evoked myogenic potential reflex as the disease progresses, although there are 
conflicting reports as to whether this occurs in Ménière's disease. Spoendlin et al. ${ }^{28}$ and Kitamura et al. $^{29}$ reported degeneration and decrease in vestibular nerve fibres, whereas Ylikoski et al. ${ }^{30}$ and Kitamura et al. ${ }^{31}$ found no such evidence.

\section{Conclusion}

The recording of vestibular evoked myogenic potentials is an emerging, non-invasive vestibular function test which can be applied to Ménière's disease. The interaural amplitude difference ratio appears to be a valuable parameter which can be used to monitor the clinical course of the disease, and in particular to identify the acute phase of Ménière's disease so as to guide appropriate treatment. However, in order to refine its clinical utility and to recommend its routine use in Ménière's disease, large, prospective, controlled, longitudinal vestibular evoked myogenic potential studies (during different phases of Ménière's disease) are required, in order to determine the sensitivity and specificity of the various vestibular evoked myogenic potential parameters.

\section{Acknowledgements}

This study was supported by a grant from the Ménière's Society (UK). The study also formed part of a thesis submitted to the University College London by the first author, as partial fulfilment for the award of an MSc in Audiological Medicine.

\section{References}

1 Committee on hearing and equilibrium guidelines for the diagnosis and evaluation of therapy in Meniere's disease. American Academy of Otolaryngology-Head and Neck and Surgery, Inc (AAOHNS). Otolaryngol Head Neck Surg 1995;113:181-5

2 McCue MP, Guinan JJ. Acoustically responsive fibres in the vestibular nerve of the cat. $J$ Neurosci 1994;14:6058-70

3 Murofushi T, Curthoys IS, Topple AN, Colebatch JG, Halmagyi GM. Responses of guinea pig primary vestibular neurons to clicks. Exp Brain Res 1995;103:174-8

4 Okuno T, Sando I. Localization, frequency, and severity of endolymphatic hydrops and the pathology of the labyrinthine membrane in Meniere's disease. Ann Otol Rhinol Laryngol 1987:96:438-45

5 Sando I, Orita Y, Hirsch BE. Pathology and pathophysiology of Meniere's disease. Otolaryngol Clin North Am 2002 35:517-28

6 de Waele C, Tran Ba Huy P, Diard JP, Freyss G, Vidal PP. Saccular dysfunction in Meniere's patients. A vestibularevoked myogenic potential study. Ann N Y Acad Sci 1999;871:392-7

7 Seo T, Node M, Yukimasa A, Sakagami M. Furosemide loading vestibular evoked myogenic potential for unilateral Meniere's disease. Otol Neurotol 2003;24:283-8

8 Seo T, Yoshida K, Shibano A, Sakagami M. A possible case of saccular endolymphatic hydrops. ORL J Otorhinolaryngol Relat Spec 1999;61:215-18

9 Young YH, Huang TW, Cheng PW. Vestibular evoked myogenic potentials in delayed endolymphatic hydrops. Laryngoscope 2002;112:1623-6

10 Wang SJ, Young YH. Vestibular evoked myogenic potentials using simultaneous binaural acoustic stimulation. Hear Res 2003;185:43-8

11 Young YH, Huang TW, Cheng PW. Assessing the stage of Meniere's disease using vestibular evoked myogenic potentials. Arch Otolaryngol Head Neck Surg 2003;129:815-18

$12 \mathrm{Wu} \mathrm{CL}$, Young YH. Vestibular evoked myogenic potentials in acute low-tone sensorineural hearing loss. Laryngoscope 2004;114:2172-5
13 Kuo S-H, Yang T-H, Young YH. Changes in vestibular evoked myogenic potentials after Menière attacks. Ann Otol Rhinol Laryngol 2005;114:717-21

14 Rauch SD, Silveira MB, Zhou G, Kujawa SG, Wall C 3rd, Guinan JJ et al. Vestibular evoked myogenic potentials versus vestibular test battery in patients with Meniere's disease. Otol Neurotol 2004;25:981-6

15 Lin MY, Timmer FC, Oriel BS, Zhou G, Guinan JJ, Kujawa SG et al. Vestibular evoked myogenic potentials (VEMP) can detect asymptomatic saccular hydrops. Laryngoscope 2006;116:987-92

16 British Society of Audiology. Recommended procedure for tympanometry. Br J Audiol 1992;26:255-7

17 Kemp DT, Ryan S, Bray P. A guide to effective use of otoacoustic emissions. Ear Hear 1990;11:93-105

18 British Society of Audiology. Recommended procedure for caloric test. Br J Audiol 1999:33:179-84

19 Rauch SD, Zhou G, Kujawa SG, Guinan JJ, Herrmann BS. Vestibular evoked myogenic potentials show altered tuning in patients with Ménière's disease. Otol Neurotol 2004;25: $333-8$

20 Todd NP, Cody FW, Banks JR. A saccular origin of frequency tuning in myogenic vestibular evoked potentials? implications for human responses to loud sounds. Hear Res 2000; 141:180-8

21 Murofushi T, Matsuzaki M, Wu CH. Short tone burst-evoked myogenic potentials on the sternocleidomastoid muscle: are these potentials also of vestibular origin? Arch Otolaryngol Head Neck Surg 1999;125:660-4

22 Welgampola MS, Colebatch JG. Characteristics of tone burst-evoked myogenic potentials in the sternocleidomastoid muscles. Otol Neurotol 2001;22:796-802

23 Node M, Seo T, Miyamoto A, Adachi A, Hashimoto M, Sakagami M. Frequency dynamic shift of vestibular evoked myogenic potentials in patients with endolymphatic hydrops. Otol Neurotol 2005;26:1208-13

24 Murofushi T, Shimizu K, Takegoshi H, Cheng PW. Diagnostic value of prolonged latencies in the vestibular evoked myogenic potential. Arch Otolaryngol Head Neck Surg 2001;127:1069-72

25 Ochi K, Ohashi T, Nishino H. Variance of vestibular-evoked myogenic potentials. Laryngoscope 2001;111:522-7

26 Alpini D, Pugnetti L, Caputo D, Cesarani A. Vestibular evoked myogenic potentials in multiple sclerosis: a comparison between onset and definite cases. Int Tinnitus $J$ 2005;11:48-51

27 Akkuzu G, Akkuzu B, Ozlouglu L. Vestibular evoked myogenic potentials in benign paroxysmal positional vertigo and Meniere's disease. Eur Arch Otorhinolaryngol 2006:263:510-17

28 Spoendlin H, Balle V, Bock G, Bredberg G, Danckwardt-Lillierstrom N, Felix $\mathrm{H}$ et al. Multicentre evaluation of the temporal bones obtained from a patient with suspected Menière's disease. Acta Otolaryngol Suppl 1992;499:1-21

29 Kitamura K, Takahashi K, Kakoi H, Sugimoto T, Silverstein H. A morphological and morphometric study of the peripheral process of the human vestibular nerve following posterior cranial neurectomy. J Laryngol Otol 1999;113:967-72

30 Ylikoski J, Collan Y, Palva T. Vestibular nerve in Menière's disease. Arch Otolaryngol 1980;106:477-83

31 Kitamura K, Kaminaga C, Ishida T, Silverstein H. Ultrastructural analysis of the vestibular nerve in Menière's disease. Auris Nasus Larynx 1997;24:27-30

Address for correspondence:

Dr Victor Osei-Lah,

61 Ridgewell Close,

London SE26 5AP, UK.

Fax: 02082962704

E-mail: vicabe@lycos.co.uk

Dr V Osei-Lah takes responsibility for the integrity of the content of the paper.

Competing interests: None declared 